\title{
Application Research on PBL Teaching Mode Based on Network Teaching Platform
}

\author{
Xun Wang \\ School of Education and Sports, Bohai University, Jinzhou, 121013, China \\ 10449434@qq.com
}

Keywords: network teaching platform; problem-based learning; PBL teaching mode; application research

\begin{abstract}
For the purpose of knowledge constructe, PBL uses a variety of resources to carry out teaching activities, improve the learning efficiency, optimize the teaching effect, emphasize autonomy, exploring and collaborative learning. In this paper, in order to carry out under the network environment of PBL teaching and research. Research content according to the theory of constructivism and humanism theory as the instruction, mainly including three aspects: one is that the group's network teaching platform function framework and main function are described; The second is, the establishment of prepared by the activities, activities to explore and evaluate summarize three stages constitute the process of PBL teaching model; Third, it is to study the PBL teaching design process, and the content of the design for the various steps. Key issues solved the PBL teaching method is studied in this paper.
\end{abstract}

\section{Introduction}

Problem-Based Learning (PBL) is a Problem oriented teaching method, is Based on the real world of student-centered education. On the basis of the subject and the traditional teaching method is different, PBL emphasizes mainly on the students' active learning, rather than in the traditional teaching is given priority to with teachers' teaching; PBL will study linked to a larger task or problem, make learners input in question; Design task authenticity, emphasize the study set to the complex, meaningful problem situation, through the learner's independent inquiry and cooperation to tackle the problem, which implied behind the problem of science knowledge, the formation of problem solving skills and the ability of autonomous learning [1,2]. Around the construction of network education environment, form a new way of digital teaching and learning, how to make the learners get maximum play to creativity and individuality, is the inevitable requirement of the current information education development. In this paper, based on the network teaching platform of PBL teaching model research, exploration to cultivate students the ability to solve the problem and the development of personalized teaching practice mode, forming a series of typical application cases and digital teaching activity design patterns, and thereby able to promote the informationization teaching organic application process, how to better promote students to learn more deeply and develop the solution of the problem.

\section{Theoretical Basis on PBL}

The basic content of PBL is shown in Fig.1. Theoretical support is mainly constructivism theory and humanistic theory.

(1) The theory of constructivism. Constructivism is a theory of knowledge and learning, emphasizes the learner's initiative, think learning is the original knowledge of learners based on generating meaning and understanding of construction, and the process is often done in the social and cultural interaction. Constructivism puts forward has a profound ideological origin, has a very different from traditional learning theory and teaching ideas, the teaching design has important guiding value. Constructivist view of knowledge view, learning view, students, teachers and students orientation, learning environment, teaching principle, teaching mode, teaching design 
concept have deeply influenced the PBL in the relevant aspects of PBL can see the shadow of constructivism is clear.

(2) The humanistic theory. Humanism emphasizes love and creativity and self-expression, autonomy, responsibility, etc, in the cultivation of psychological quality and personality characteristics of modern education has had a profound effect. Maslow as the founder of humanistic psychology, fully recognized human dignity and value, actively advocates the realization of the potential. Rogers, another important representatives also emphasized self-expression, emotion and subjectivity. He thinks that the goal of education is to cultivate a sound personality, to create a positive growth environment. Humanism theory is that emotional and cognitive is an organic part of an integral in human spiritual world, is be in harmony with each other, is also a "whole person" should have two aspects. In order to develop the "whole person", the teacher must take effective methods to promote the change of students and learning, cultivate the ability to adapt to change and know how to learn.

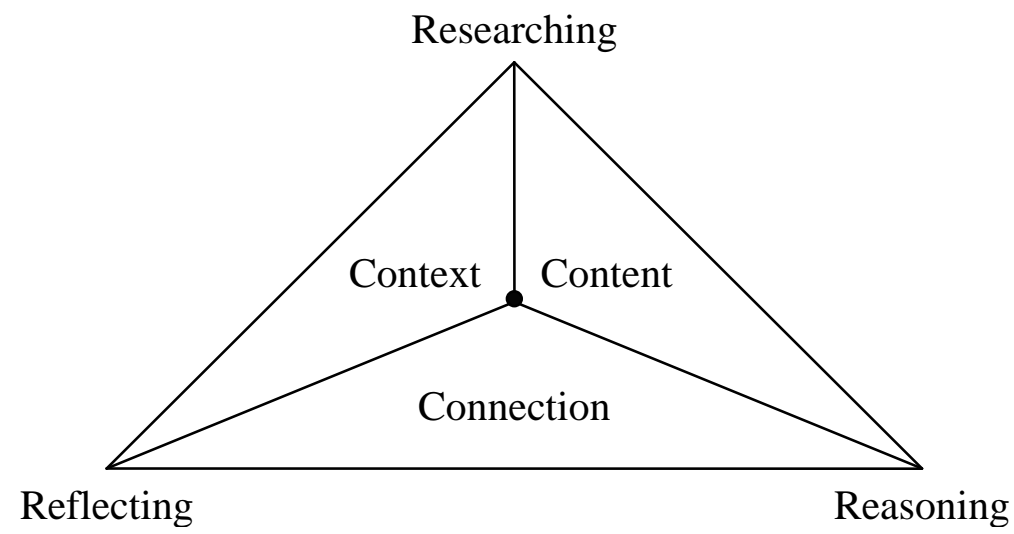

Fig. 1. Basic content on PBL

\section{Functional Framework on PBL Network Teaching Platform}

Function design of the most commonly used method is MoNiHua, functional framework is the result of the modular structure. Frame structure is the system function decomposition, according to the functional dependency said graphics, each rectangular box in this picture is called a function module. Functional decomposition process from big to small, from coarse to fine, from top to bottom. Conceptually, upper function to control the lower, upper function more generally, the lower the specific function. Functional decomposition process is a from abstract to concrete, from complex to simple process. Function module can according to the specific situation of larger or smaller, decomposition to the minimum of each function module can be a program in the process, and the larger function module can complete a task is a set of procedures. PBL network teaching platform mainly includes two categories, "students" and "teacher", "learning project" as the core study, functional framework is shown in Fig.2 [3, 4].

For the main functional description as shown in Fig.2 is as follows: (1) the problem situation, is the characterization of the problem. Using the network multimedia technology, the use of animation form, and with sound, presents the realistic problem situation, to the student and problem description is given. (2) the problem analysis, provide a problem space. Students through the analysis of the problem situation, and puts forward some related to the situation, they are interested in the problem, and to confirm the problem, determine the known and unknown information in question. (3) learning resources, including courseware resources, image resources and network resources. Courseware resources are mainly about research project content, including electronic slides and Flash animation; Image resources is the study of project related images; Network resources is provided can query to the information on the Internet links. (4) the problem solving and involve the students specific network problem solving activities, mainly including information query, solutions to problems associated with problem formulation, and the division of tasks between team members, etc. (5) communication collaboration, is mainly a BBS BBS, students using the 
Internet platform for problem solving activities is the main place, can achieve a pair of free exchange, one-to-many communication and group communication. (6) the results of evaluation, the comprehensive evaluation on the learning outcomes. Through results show to see results, through sharing implementation achievements to serve more people, through the evaluation of reflection to get the evaluation results and lessons learned.

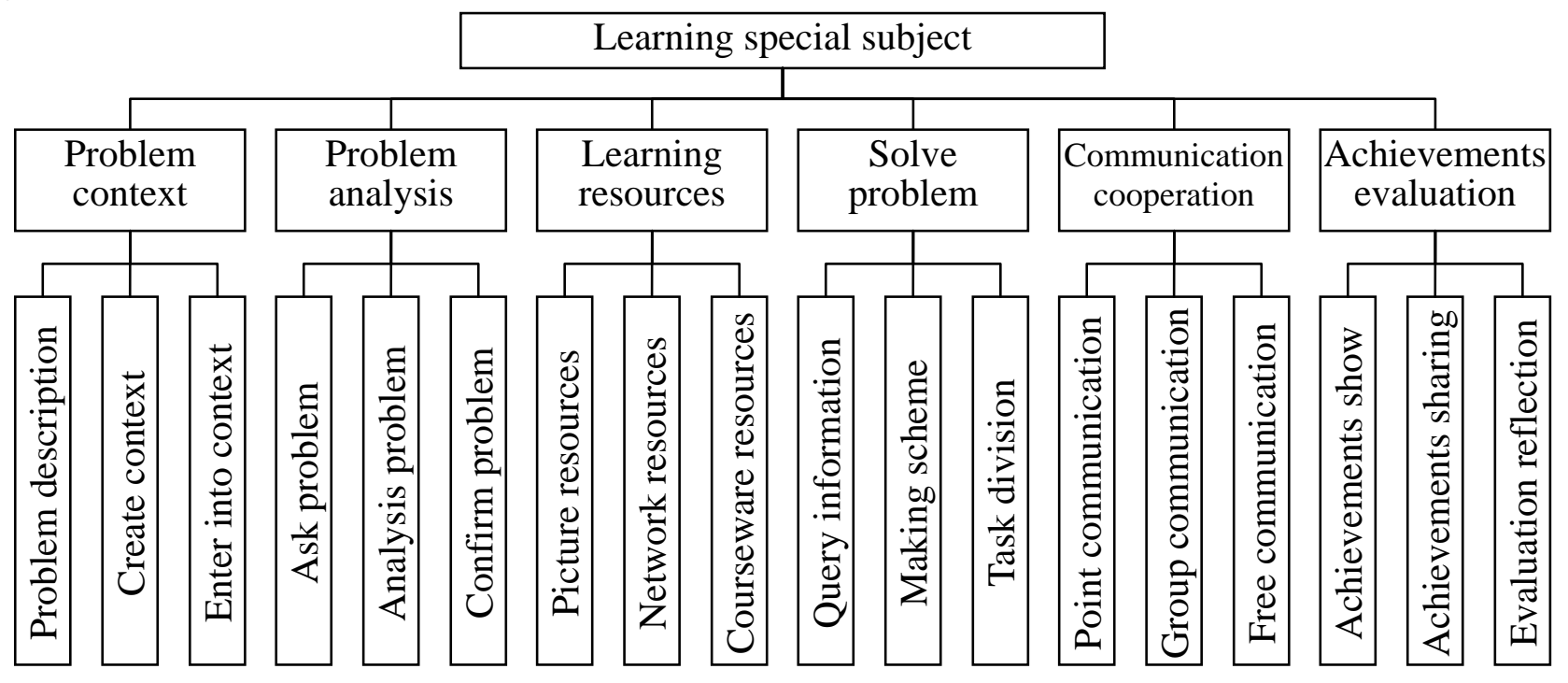

Fig. 2. Functional framework on PBL network teaching platform

\section{Teaching Model on PBL}

PBL teaching process including preparation, activities to explore and evaluate summarize three stages, completion of the main body of teaching process, including teachers and students, teaching process model as shown in Fig.3 [5].

\section{Teaching Design on PBL}

Teaching design is according to the requirement of the curriculum standard and teaching object, the characteristics of integrating all teaching factors in an orderly arrangement, determine the right idea of teaching plan and program. Teaching design has the following characteristics: the teaching design is to put the theory into teaching materials and teaching plan, should follow the basic law of teaching process, choose the teaching goal, to solve the problem of what to teach; Teaching design is to realize the teaching goal of planning and decision-making activities, in the form of plan and layout arrangement, on how to achieve the teaching goal for creative decisions, in order to solve the problem of how to teach; Teaching design guided by the systematic approach to the elements of teaching as a system, analysis of teaching problems and needs, establishes the procedures by solving an outline, optimize the teaching effect; Teaching design is to improve the efficiency of the learners acquire knowledge, skills, and interests of technology process, is a component part of education technology, the function is a systematic method to design the teaching process, make it become a kind of operational procedures. PBL teaching design process as shown in Fig. 4.

(1) Related factors analysis. Including the analysis of students, teachers and teaching resources, etc. Analysis of students, mainly includes the knowledge structure, cognitive level, learning needs and learning attitude and so on; Teachers' analysis, mainly including the knowledge structure, knowledge level, teaching experience and teaching attitude; All kinds of teaching resources, mainly including the auxiliary teaching software and hardware resources, including the teaching place, multimedia equipment, computer network and software platforms.

(2) The study theme design. "Theme" as the core of learning, and around the theme of structured content become the main object of study. To break the disciplinary boundaries around a topic to study and explore, will involve different disciplines, issues, and the content of the activity, need to 
be integrated application of multidisciplinary knowledge to solve the problem. Studying theme design is related to the whole learning process, to achieve the goal of learning and the ability of learners.

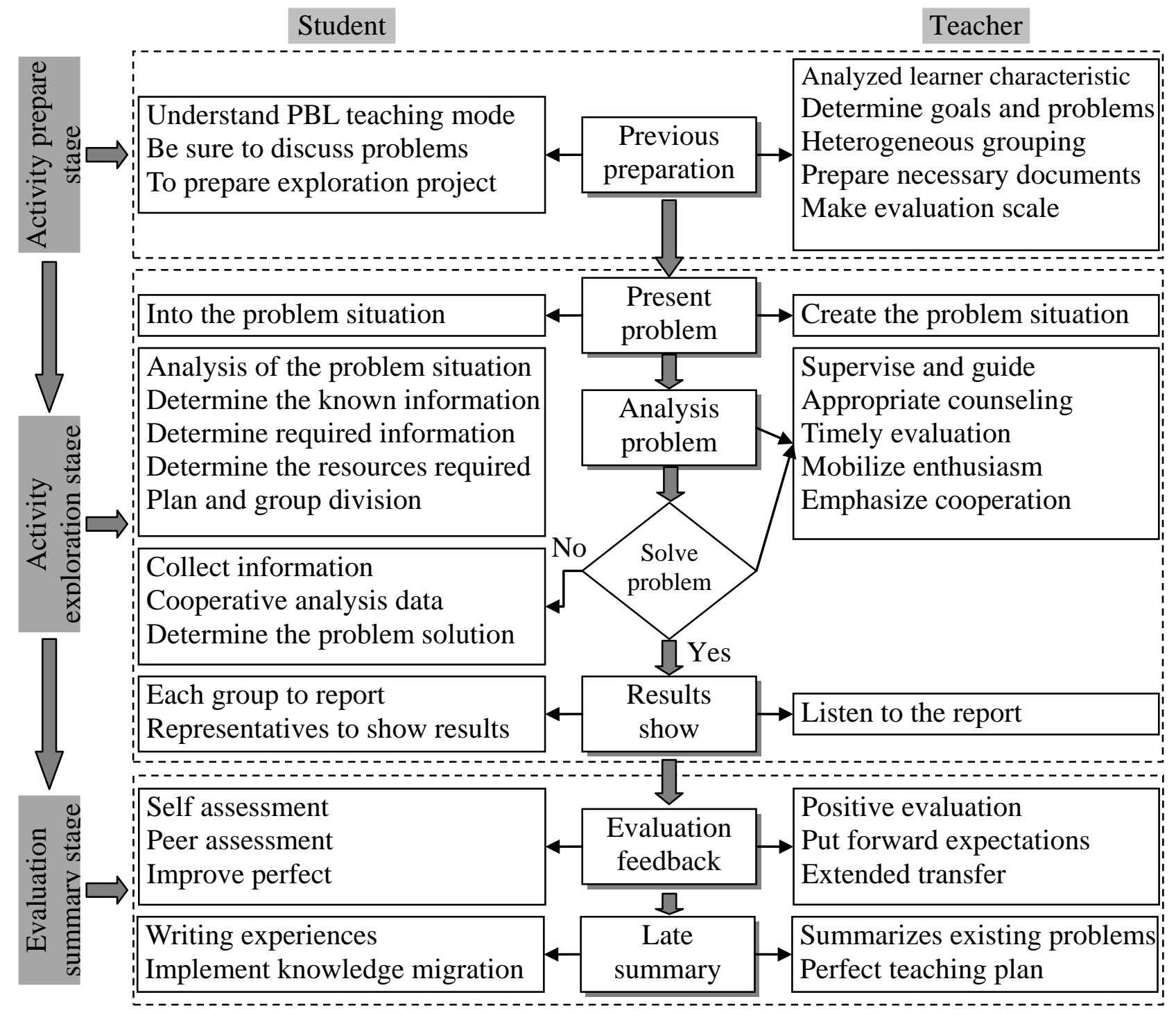

Fig. 3. Teaching process model on PBL

(3) The learning objective design. Learning goal refers to learners through a series of learning activities to achieve expected results, is the embodiment of education purpose, organization, design, implementation and evaluation of the starting point of teaching activities. In PBL teaching, the students need clear learning objectives, the teaching goal should be included in the design of the teacher's questions or case. Under the network environment, mainly cultivate students ability to problem solving and knowledge construction.

(4) The learning environment design [6]. Learning environment is the external environment affecting the learners' learning, learning activities under the network environment is the sum of all the external conditions, is the foundation and guarantee for the effective learning activities. Learning environment can effectively support the learners' learning activities, learners can fix the problem is one of the important factors, including the problem situation, learning objectives, learning resources and learning tools design.

(5) Design the learning activities[7]. Refers to the learners' learning activities and the related study group in order to complete the specific learning goals for the combined operation. Learning activity design final performance for the design of the learning task, by rule learners to complete the mission objectives, results, forms, content, activity within the strategies and methods to induce the learners cognitive processing and thinking, so as to achieve the goal of developing learners' 
psychological function. Learning activity design includes the design of the task, the process design of activities, activity rules and design for evaluation and so on four basic link.

(6) Learning evaluation design. The feedback regulation mechanism of learning evaluation as a learning system, plays an important role in the process of learning and teaching, is one of the most important aspects of the education experts and psychologists study. PBL in value result evaluation at the same time, pay more attention to process evaluation. Per formative evaluation to promote students' learning, to better supervise the learning process. For overall assessment need through self-evaluation, group evaluation and expert evaluation weighted method to calculate.

(7) Supervision and design study. According to the situation of students' learning and academic achievements, lets the student in the PBL learning environment from the network or other aspects of monitoring measures. Such as the frequency statistics student exchange information, the frequency of the access to the learning environment for learning, and learning content classification statistics, etc.

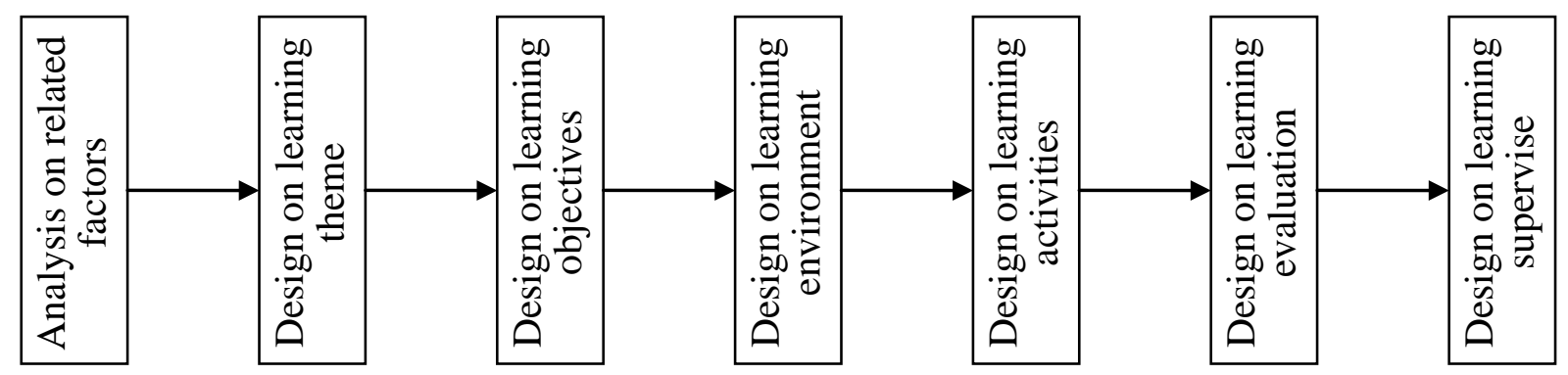

Fig. 4. Teaching design process on PBL

\section{Conclusion}

Under the new curriculum reform tide, the organic integration of information technology and curriculum, to better realize the goal of the new curriculum reform, cultivate the students' innovation spirit and practice ability and the desire and ability of lifelong learning, promote students' all-round development provides a great convenience, is also a effective way to realize the goal of the new curriculum reform and the task of. In order to promote information technology under the background of the application of PBL teaching model and carry out research in this paper. Using this article research, to develop the teaching of problem oriented method, take the student as the main body, teachers oriented heuristic education, to cultivate the students' ability as the teaching goal, give full play to the questions on the guidance of the learning process, to mobilize students' initiative and enthusiasm.

\section{Acknowledgement}

This work is supported by Education science planning project in Liaoning province (JG14DB022): Application Research on PBL Teaching Mode Based on Network Teaching Platform.

\section{References}

[1] Y. Zhao, "Application of PBL Teaching Mode in Ideological and Political Theory Course," Journal of Shenyang University (Social Science), vol. 17, no. 6, pp. 792-795 2015.

[2] Y. Liu, "Problems and solutions with PBL mode in medical education," Basic Medical Education, vol. 17, no. 8, pp. 694-696, 2015.

[3] Y. J. Wang, "Application of PBL in practical teaching of Multimedia Technology and Application course," Experimental Technology and Management, vol. 32, no. 10, pp. 188-192, 2015. 
[4] Q. Tu, "Analysis of PBL teaching model on students' autonomous learning effect Meta," Journal of Shengli College China University of Petroleum, vol. 29, no. 4, pp. 63-66, 2015.

[5] S. L. Song, "The innovation of practice teaching mode in Colleges and Universities Based on PBL," Heilongjiang Education (Higher Education Research \& Appraisal), vol. 71, no. 1, pp. 55-56, 2016.

[6] N. Ding, "The design of learning environment PBL under network environment," Guide of Sci-tech Magazine, vol. 19, no. 20, pp. 57, 2011.

[7] X. W. Chen, "The design and application of online learning activities PBL: taking the course of educational technology research methods for example," China Information Technology Education, vol. 16, no. 11, pp. 117-119, 2015. 